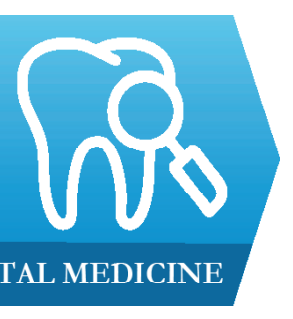

DENTAL MEDICINE

\title{
Jaw relationship assessment for removable complete dentures using the t-scan computerised system - a case report
}

Szidónia Renáta Akácsos ${ }^{1}$, Melinda $\mathrm{Kis}^{2}$, Melinda Székely ${ }^{3}$, Sorin Popşor ${ }^{4}$, Kinga Dörner ${ }^{4}$

1) Faculty of Dentistry, University of Medicine, Pharmacy, Sciences and Technology of Tirgu-Mures, TirguMures, Romania

2) CMI Dental Practice Dr. Nagy Imre, Oradea, Romania

3) Department of Morphology of Teeth and Dental Arches; Technology of Dental Prosthesis and Dental Materials, Faculty of Dental Medicine, University of Medicine and Pharmacy, Sciences and Technology of TirguMures, Tirgu-Mures, Romania

4) Department of Removable Prosthetic Dentistry, Faculty of Dental Medicine, University of Medicine and Pharmacy, Sciences and Technology of TirguMures, Tirgu-Mures, Romania
DOI: $10.15386 / \mathrm{mpr}-1522$

Manuscript received: 03.07.2019 Received in revised form: 16.09 .2019 Accepted: 04.11.2019

Address for correspondence: akacsos.szidonia93@gmail.com

\begin{abstract}
Objective. For obtaining the perfect balance of a removable complete denture, we have a few clinical procedures to complete, but only the analysis of the occlusal load distribution at various vertical dimensions of occlusion can give us the precise data.

Method. The patient selected for this case report was a 35 years old edentulous female who requested prosthetic treatment with complete removable dentures. We followed the usual clinical steps of obtaining an acrylic denture, as well as the T-Scan III analysis during the jaw registration, in different conditions: with the occlusal wax rims, and with the trial denture in the next step, registering three different occlusal vertical dimension - understated, overstated and ideal height. Using these dimensions, we realized four mock-ups, two at the proper vertical dimensions, with various types of tooth color and shape. We analyzed the mock-ups using the T-scan III system. After the dental prosthesis was manufactured, we made another measurement with the T-scan III system.
\end{abstract}

Results. After analyzing all the data from the T-scan III system, we distinguished that the most suitable solution for the patient was the proper dimension mock-up with D2 shade.

Conclusions. Although the registered situations were satisfactory, the aesthetic issues are essential, and the functional aspects are fundamental, the most suitable solution in this case, was the mock-up with proper dimensions.

Keywords: computerized occlusal analysis, T-Scan System, bilateral balance, complete removable denture, aesthetics

\section{Introduction}

One of the most significant challenges during the treatment with complete removable dental prostheses is obtaining the bilateral balance [1]. The most frequent obstacle that can affect this procedure is the soft tissue resiliency, although using advanced mechanical appliances like semi-adjustable articulators; these can only approximate the occlusal functional movements [2].

Fortunately, modern technology offers a solution to this problem with computerized occlusal analysis the T-Scan System, a diagnostic device that can register a patient's bite force, occlusal force location and timing $[3,4]$.
A pressure-mapping sensor records intraorally the biting force dynamics and the data is stored on a hard drive that can be played back in video format [5]. The T-scan III system analyses the order of the occlusal contacts, and measures the percentage of the force changes and the efficiency of the occlusion from the first occlusion contact through to maximum intercuspation $[6,7,8]$.

We can use the T-Scan system during the treatment with a complete removable denture to analyze and measure occlusal forces, and with the computer-guided corrective adjustments, the occlusal balance can measurably improve $[9,10]$. 


\section{Case report}

The case study was conducted on a 35 years old edentulous female patient who agreed to participate and gave her consent to use her personal details. She requested a prosthetic treatment with complete removable acrylic dentures. She claimed that she lost her teeth during her multiple pregnancies, and she has digestive problems due to mastication difficulties. The patient suffered from complications such as masticatory disorders, feature changes, pronunciation difficulties and psychological impacts [11].

The examination of the jaw support area reveals a high and wide maxillary and mandibular ridge, a deep palatal vault, well-represented tuberosities providing excellent support and stabilization conditions.

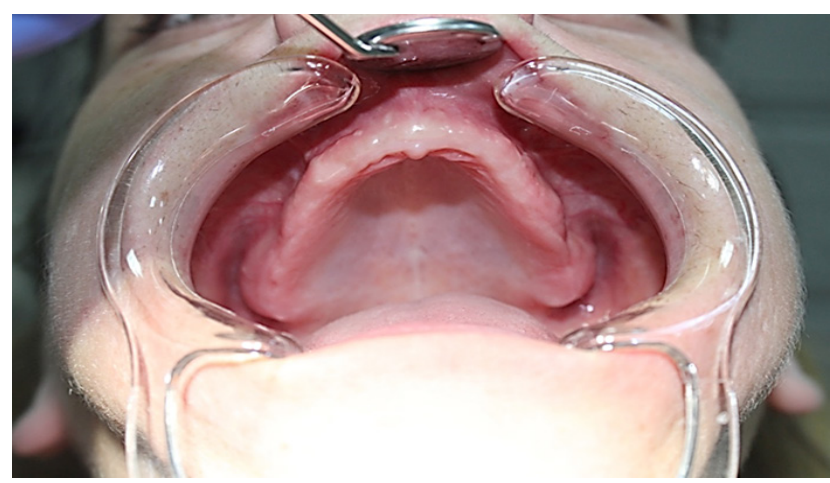

Figure 1. The maxillary ridge.

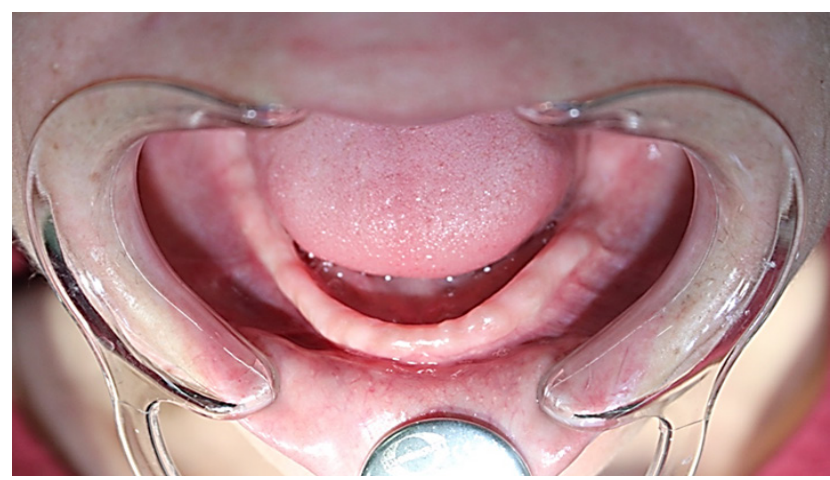

Figure 2. The mandibular ridge.

We followed the usual clinical steps of obtaining an acrylic denture, and we introduced the T-Scan III system during the treatment. Based on the functional impressions, the technician made the final models on which we made three pairs of occlusal wax rims [12,13]. Using these wax rims, we established three vertical dimensions: understated, ideal and overstated, and we registered them using the T-scan system.

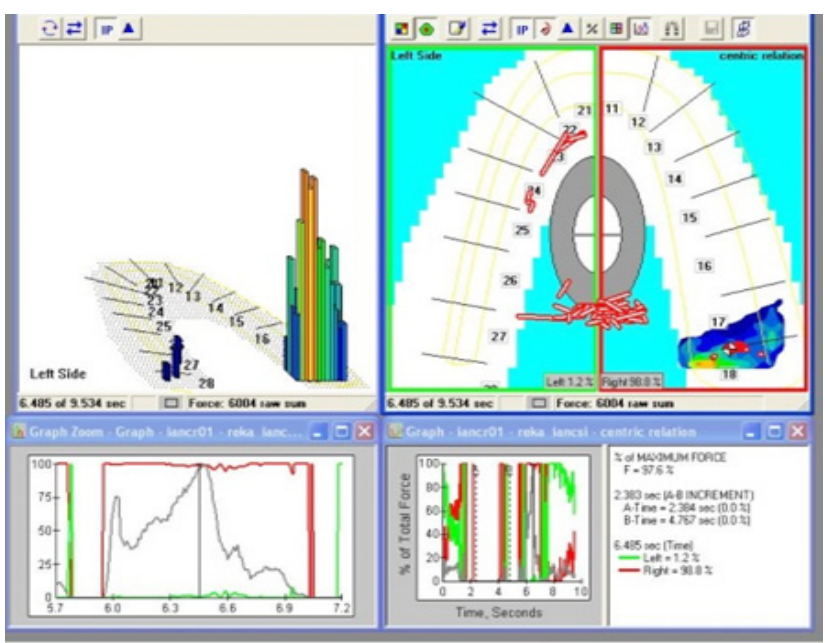

Figure 3. The T-scan registration at lower vertical dimension.

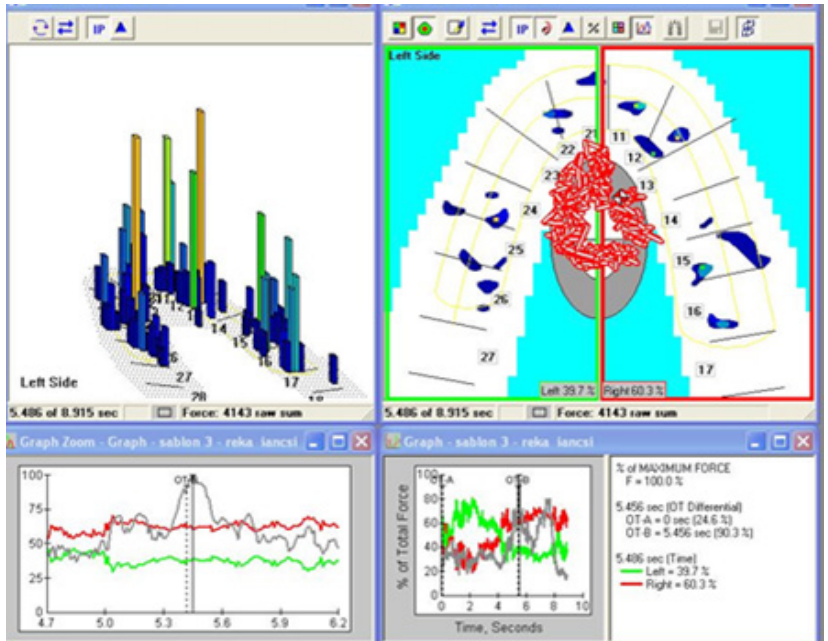

Figure 4. The T-scan registration at higher vertical dimension of occlusion.

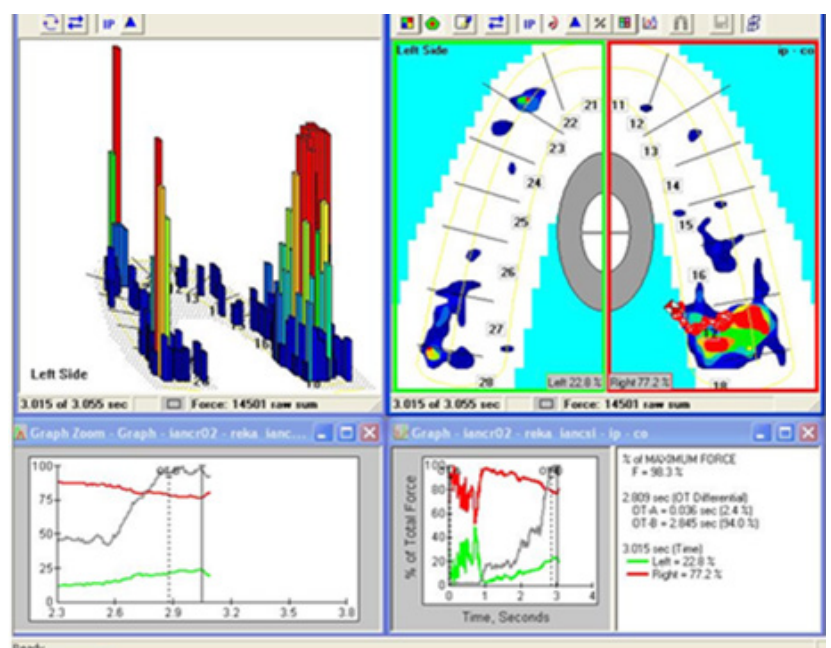

Figure 5. The T-scan registration at the correct vertical dimension. 
Using the set dimensions, the technician made four mock-ups: two in perfect vertical dimensions, one with understated aspects and one with overstated vertical

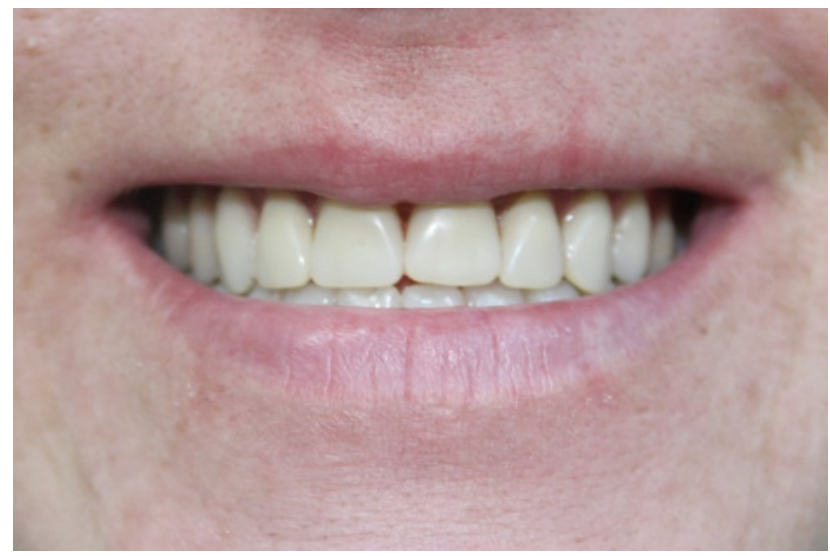

Figure 6. The mock-up with underevaluated vertical dimension. The New Ace-Yamahachi acrylic teeth col. D3.

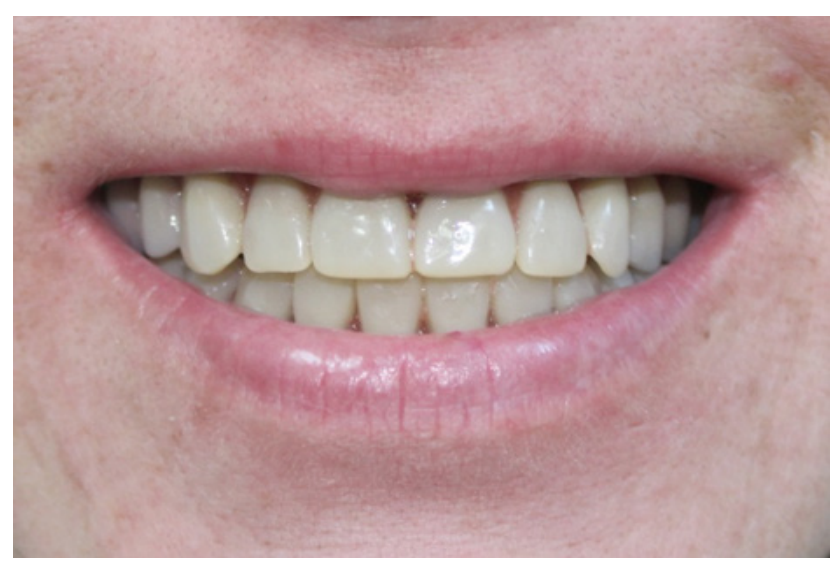

Figure 8. The mock-up with ideal vertical dimension. The Eray Deluxe acrylic teeth col. C4.

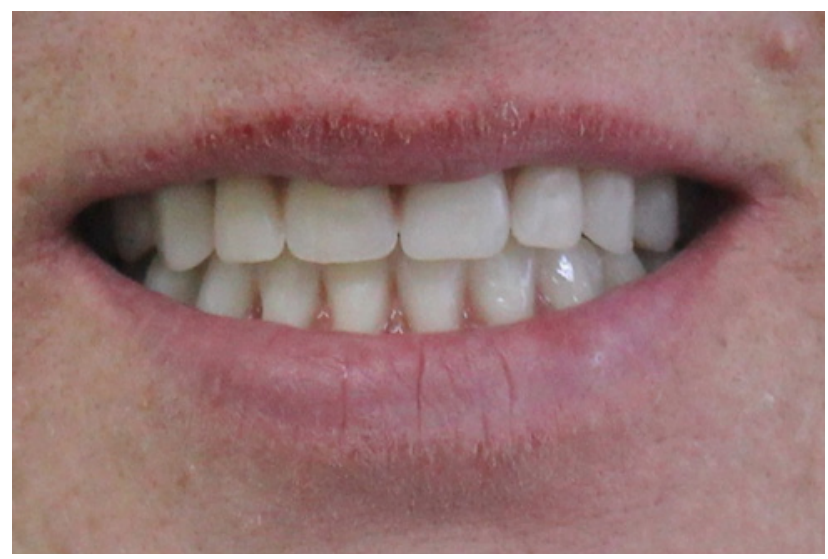

Figure 10. The mock-up with ideal vertical dimension. The Wiedent acrylic teeth, colour D2. dimensions. We used various acrylic teeth in shape, color and brand.

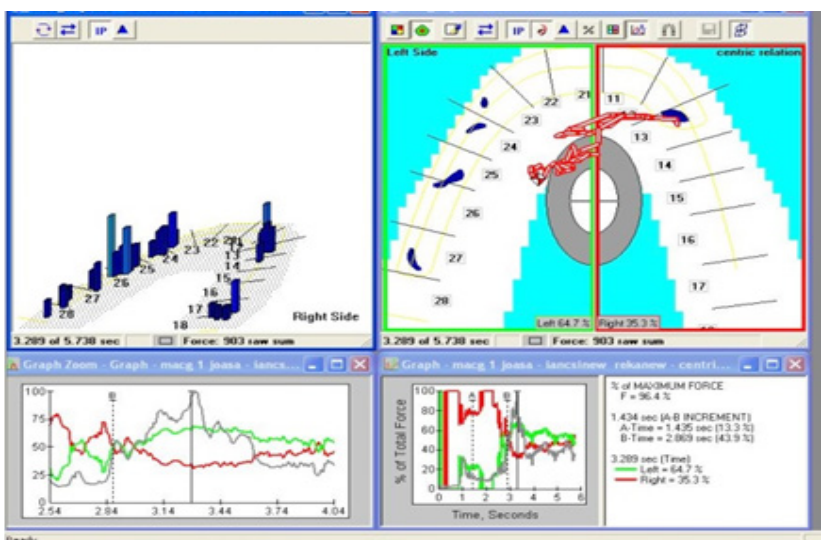

Figure 7. The T-scan mock-up with higher vertical dimension.

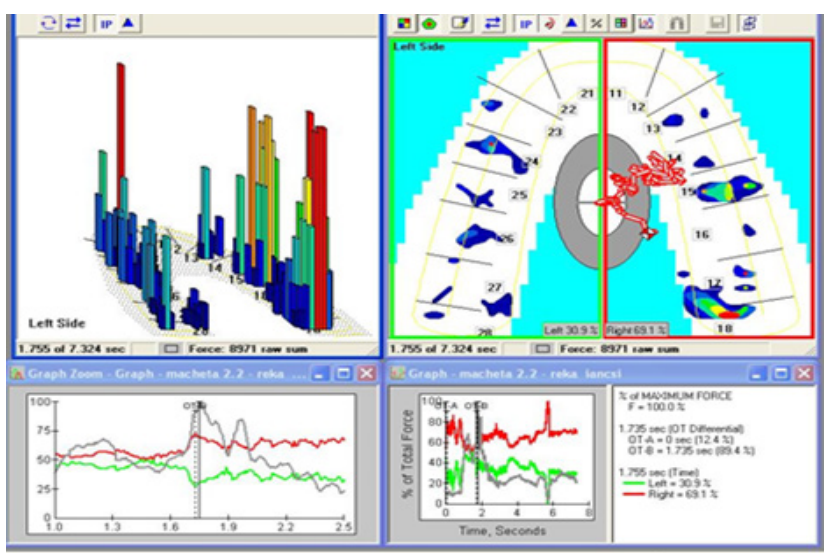

Figure 9. The T-scan with the ideal vertical dimension.

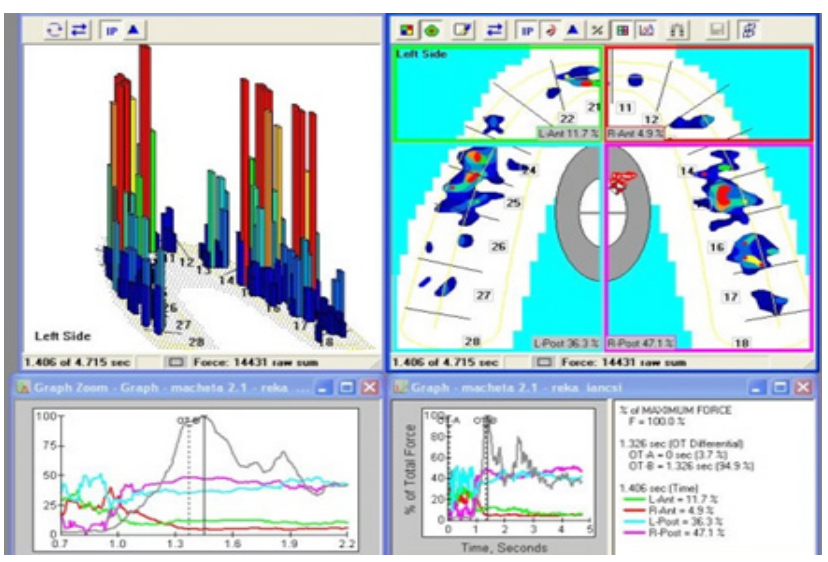

Figure 11. The T-scan mock-up at the ideal vertical dimension. 


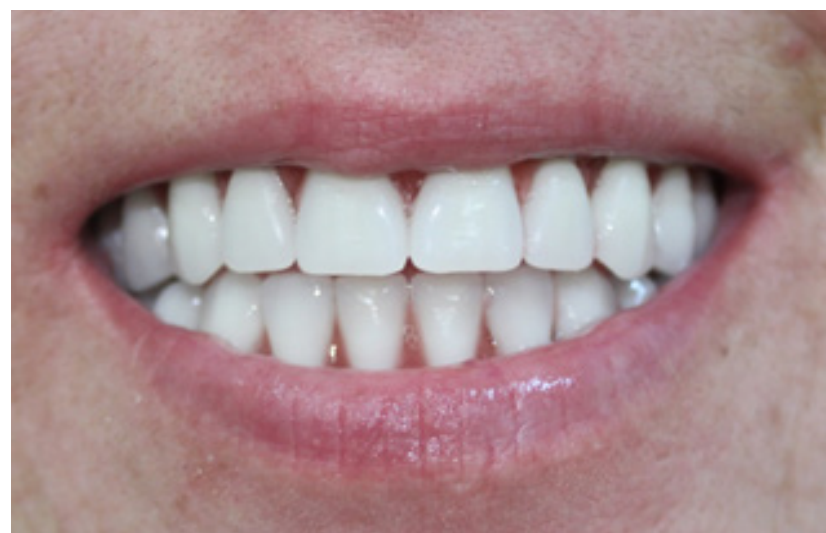

Figure 12. The mock-up with higher vertical dimension. The New Ace-Yamahachi acrylic teeth colour B1.

Analyzing all the data from the T-scan registrations we distinguished that the most suitable solution for the patient was the proper dimension mock-up with Wiedent acrylic teeth, color D2. When the prosthesis was finished we registered it with the T-scan system before and after

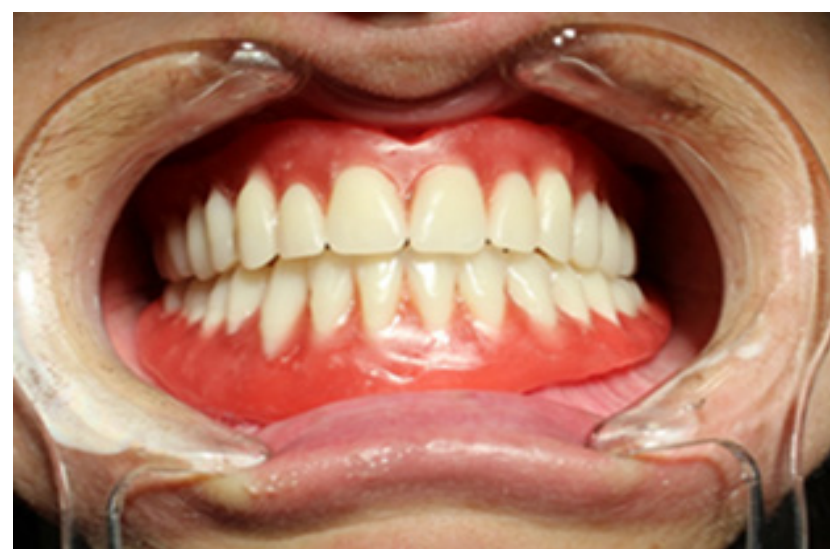

Figure 14. Mock-up.

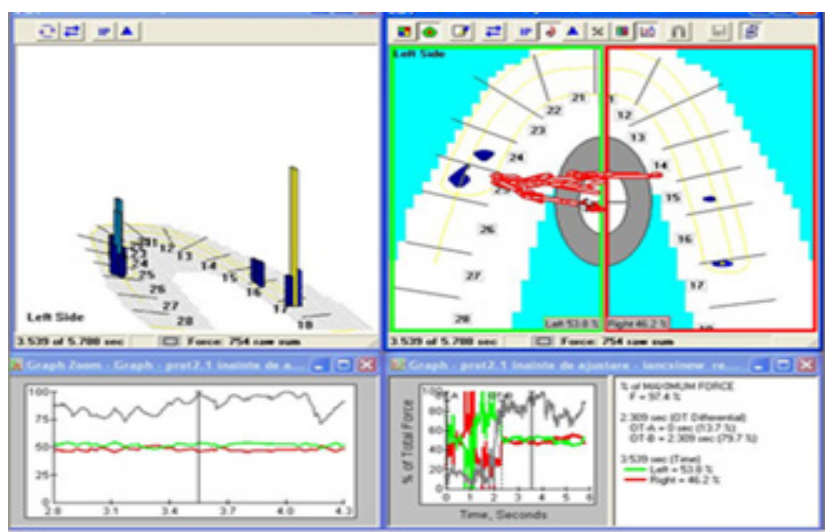

Figure 16. T-scan with the final prosthesis before occlusal adjustments.

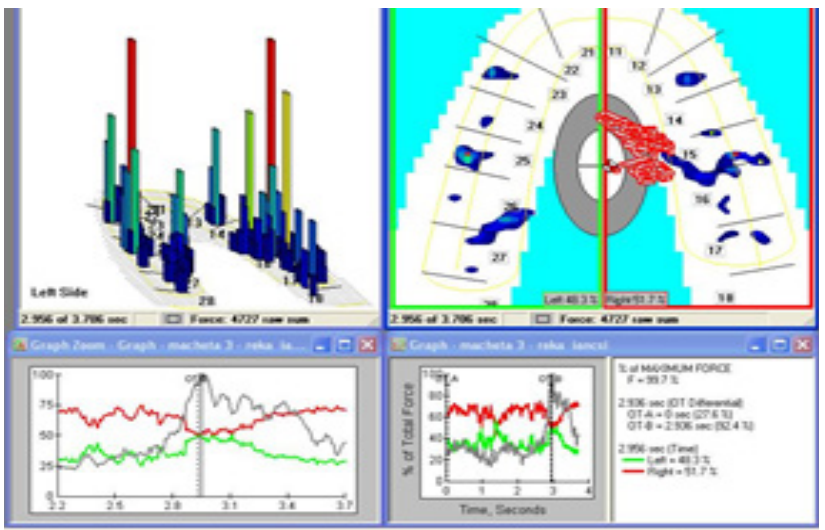

Figure 13. The T-scan mock-up at the overstated vertical dimension.

the corrective adjustments. The T-scan system indicated the areas where we had to make adjustments to obtain the bilateral balance, using this device made this procedure easier. After seven months the patient returned for a review, and we made another registration with the T-scan system.

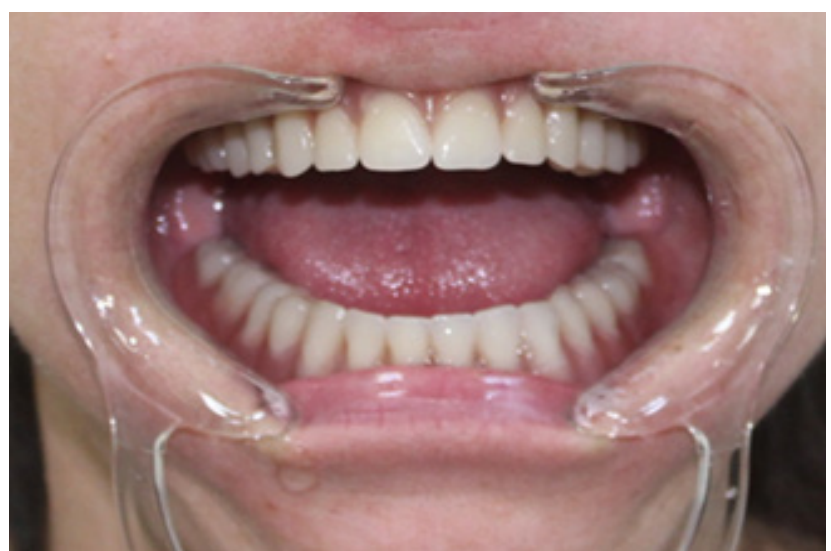

Figure 15. The final denture.

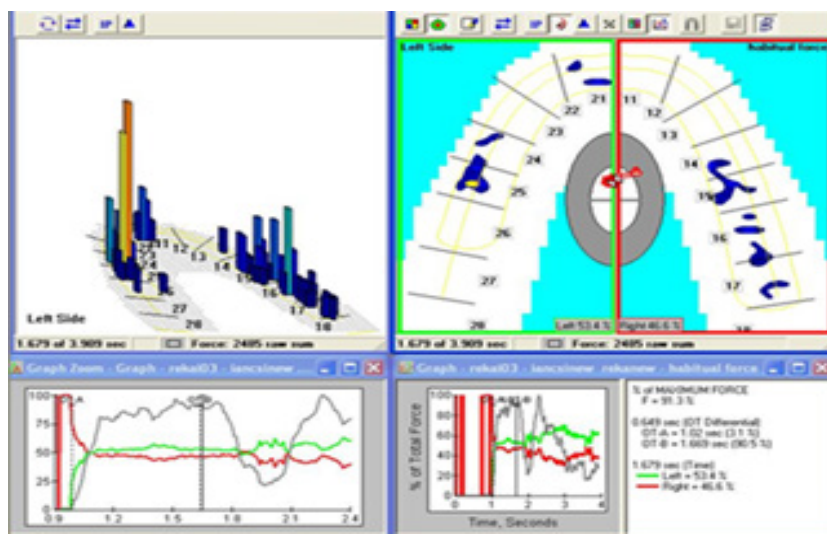

Figure 17. T-scan after occlusal adjustments. 


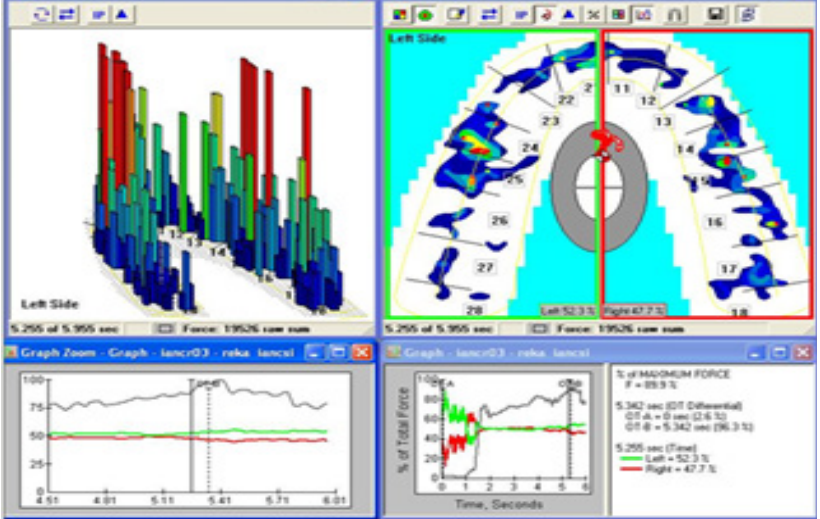

Figure 18. T-scan evaluation after seven months.

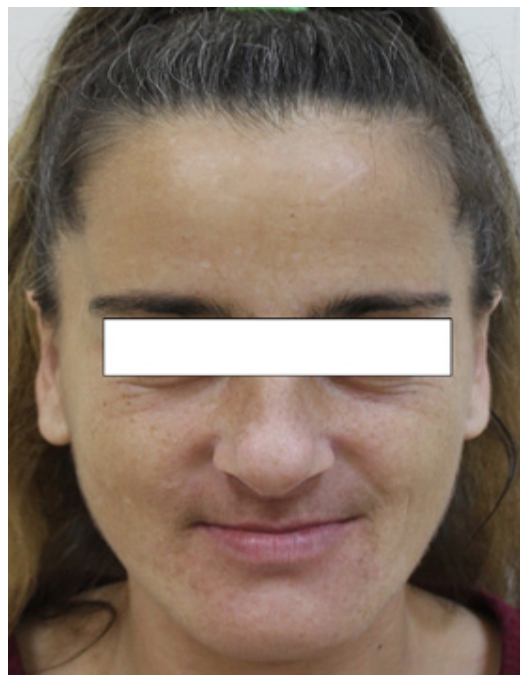

Figure 19. Patient before the treatment.

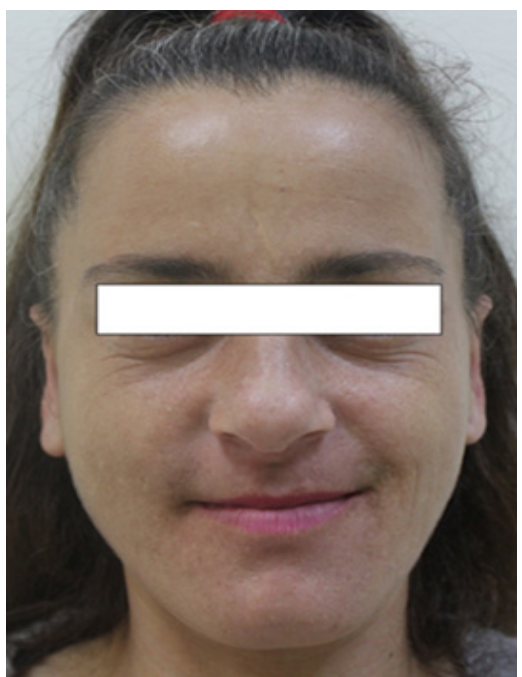

Figure 21. Patient after the treatment.

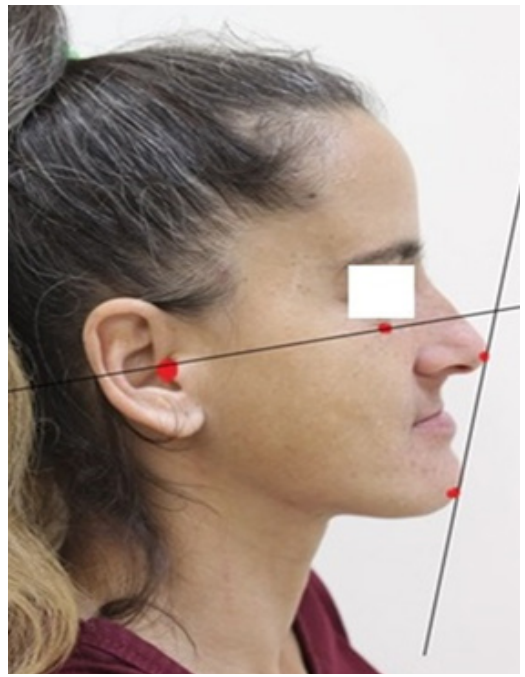

Figure 20. Edentulous profile.

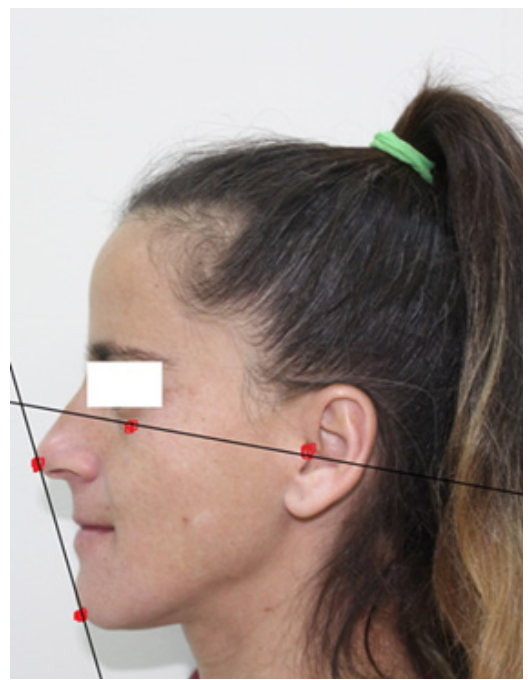

Figure 22. Patients profile after treatment. 


\section{Discussion}

Analyzing all the data from the T-scan recordings with the occlusal patterns, mock-ups and the final acrylic prostheses we noticed the following:

- In the case of the understated occlusal design (Figure 3), 98.8\% of the occlusal forces are focused on the right side (red line) while the left side (green line) occupies only $1.2 \%$ of the occlusal force.

- In the case of the occlusal pattern with ideal vertical dimensions (Figure 4), the occlusal forces are concentrated $77.2 \%$ on the right side (red line), and approximately $22.8 \%$ on the left side (green line).

- In the case of the occlusal pattern with overstated vertical dimensions (Figure 5), $60.3 \%$ of the occlusal forces are on the right side, and $39.7 \%$ on the left.

- In the case of the mock-up with understated vertical dimensions and New Ace-Yamahachi acrylic the D3 color (Figure 6, Figure 7), 64.7\% of the occlusal forces are focused on the left (green line) and $35.3 \%$ on the right side (red line).

- In the case of the mock-up with ideal vertical dimensions and Eray Delux acrylic the color C4 (Figure 8, Figure 9), $48 \%$ of the occlusal forces are on the left (green line) and $52 \%$ on the right side (red line).

- In the case of the mock-up with ideal vertical dimensions, Wiedent acrylic teeth color D2 (Figure 10, Figure 11 ), $30.9 \%$ of the forces are on the left, $69.1 \%$ on the right (red line).

- In the case of the mock-up with overstated dimensions and New Ace acrylic teeth color B1 (Figure 12, Figure 13), $48.3 \%$ of the occlusal forces are on the left and $51.7 \%$ on the right side.

- In the case of the prosthesis before the adjustments, $53.8 \%$ of the occlusal forces are on the left (green line) and $46.2 \%$ on the right side (red line). The center of the force is outside the white and grey circles (Figure 16).

- In the case of the prosthesis after adjustments, $53.4 \%$ of the occlusal forces are on the left (green line) and $46.6 \%$ right side (red line), but the center of the force is inside the white circle (Figure 17).

- The evaluation after seven months showed us that the occlusal forces were on $52.3 \%$ on the left (green line) and $47.7 \%$ on the right side (red line). The two lines coincide on a section, which means that the prosthesis is balanced; the center of the force is in the white and grey circles (Figure 18).

The reason why we used different acrylic teeth is that we tried to demonstrate the importance of aesthetics, which is an essential aspect in the treatment. By making mock-ups using different acrylic teeth in different colors and shapes, we tried to re-think how important it is to choose the color and shape that matches the patient according to sex, skin shades, age and face features.
Although the registered situations were satisfactory, the aesthetic issues are essential, and the functional aspects are fundamental, the most suitable disentanglement, in this case, was the mock-up with proper dimensions.

\section{References}

1. Kerstein RB, Thumati P, Padmaja S. Force Finishing and Centering to Balance a Removable Complete Denture Prosthesis Using T-Scan III Computerized Occlusal Analysis System. J Indian Prosthodont Soc 2013;13:184-188.

2. Olivieri F, Kang KH, Hirayama H, Maness WL. New method for analyzing complete denture occlusion using the center of force concept: a clinical report. J Prosthet Dent. 1998;80:519-523.

3. Throckmorton GS, Rasmussen J, Caloss R. Calibration of T-Scan sensors for recording bite forces in denture patients. $\mathrm{J}$ Oral Rehabil. 2009;36:636-643.

4. Sierpinska T, Golebiewska M, Kuc J, Lapuc M. The influence of the occlusal vertical dimension on masticatory muscle activities and hyoid bone position in complete denture wearers, Adv Med Sci. 2009;54:104-108.

5. Jin-Hwan K. Computerized Occlusion Using T-Scan III, e-book, 2016. Available from: https://www.tscan.nl/wpcontent/uploads/2016/12/DTL-T-Scan-Clinical-eBook.pdf

6. Kim KA, Oh WS, Lee JJ. Recording an accurate maxillomandibular relationship by adding vertical stops to the occlusal rims. J Prosthet Dent. 2019;121:242-245.

7. Yanikoğlu ND, Güldağ MU, Duymuş ZY. Determination of the occlusal vertical dimension: use of maxillary and mandibular posterior teeth measurement in edentate subjects. Eur J Prosthodont Restor Dent. 2005;13:75-77.

8. Foong KW, Patil PG. Fabrication of maxillary single complete denture in a patient with deranged mandibular occlusal plane: A case report. Saudi Dent J. 2019;31:148-154.

9. Nabeshima F, Tanaka M, Kawano W, Saratani K, Yanagida M, Kawazoe T. The balance of occlusal contacts during intercuspation using T-scan system. Nihon Hotetsu Shika Gakkai Zasshi. 1990;34:340-349.

10. Kuswah A, Mukesh K, Avinashi J, Shreya P. T-scan - A digital occlusal analyzer, TMU J Dent 2017;4(4):165-167.

11. Oprea L. Un studiu analitic asupra relaţiei medic-pacient [An analytical study on the doctor-patient relation], part II, Revista Română de Bioetică, 2009;7:53-64.

12. Tarazi E, Ticotsky-Zadok N. Occlusal schemes of complete dentures - a review of the literature, Refuat Hapeh Vehashinayim (1993). 2007;24:56-64, 85-86.

13. Popşor S, Coman LM, Biriş C. Diagnostic și tratament în edentația totală [Diagnosis and treatment of total edentation]. Ed. University Press Târgu-Mureș, 2010.

14. Radnai M. - Részleges, kivehető fogpótlások, Ed. Medicina, Budapest, 2012, 165-166.

15. Molnar-Varlam C, Chifor A, Székely M. Protezele dentare mobile și mobilizabile aspecte technice [Mobile and movable dental prostheses - technical aspects]. Ed. University Press Târgu-Mureş, 2016: pp. 18-21, 47-49. 